\title{
EDUCAÇÃO A DISTÂNCIA: UMA ANÁLISE DOS MODELOS DE ENSINO
}

Arlindo Fernando Paiva de Carvalho Júnior | professor_ead_efe@hotmail.com

Pós-graduado em Planejamento, Implementação e Gestão da EAD pela Universidade Federal Fluminense (UFF). Professor de Educação Física e tutor presencial do curso de licenciatura em pedagogia no consórcio CEDERJ.

\section{Resumo}

A educação pode se manifestar em diferentes modalidades de ensino, como a $\mathrm{EaD}$, que está sendo ampliada entre as instituições educacionais e está vencendo barreiras impostas à educação. O crescimento acelerado da EaD faz com que diferentes modelos de ensino na modalidade surjam no cenário educacional. O presente artigo foi desenvolvido com base em pesquisa e revisão literária das obras clássicas e atuais que abordam o tema educação a distância em sua ampla dimensão, tendo como foco de estudo os modelos de ensino em EaD, onde foram investigadas suas características, como as formas de interação. A pesquisa teve caráter teórico, exploratório e social, pois buscou informações sobre uma modalidade de educação específica. Esta pesquisa não se esgota aqui, pois os modelos tendem a se transformar, a se adequar às futuras tecnologias, o que implicará o surgimento de novos modelos de ensino.

\section{Palavras-chave}

Educação a Distância. Modelos de ensino. Formas de interação. 


\section{Distance Education: a Teaching/ Learning Models Analysis}

\begin{abstract}
Education can happen in different ways of teaching/learning like DL (distance learning), for example, which has become an issue among the education institutions, and it has broken down barriers against education, such as: the lack of structure, time and adequate material to student. The fast growing of $\mathrm{DL}$ leads to a way in which different materials of teaching/ learning are created in the distance learning scenario. This article was developed based on researches and on the analysis of the most consecrated and actual literature which deals with distance education in its general dimension having its focus on the teaching models in which its characteristics were investigated, such as how different ways of interaction take place. The research had a theoretical, social and exploratory basis since it deals with a specific educational modal. This research is not closed and seen as "done" as learning models tend to change, to adapt to future technologies which implies the growth of new learning models.
\end{abstract}

\section{Keywords}

Distance learning. Teaching models. Ways of interaction.

\section{Introdução}

O que é modelo de ensino em $\mathrm{EaD}$ ?

Quando pensamos em modelos de ensino, pensamos em padrões prontos a serem seguidos quanto à estruturação e organização educacional, porém não podemos reduzir nossos olhares a visões tão simplistas. Os modelos de ensino traduzem a filosofia da instituição de forma implícita; os modelos estão impregnados de princípios e valores que devem ser levados em consideração.

Segundo o Microdicionário Ruth Rocha (1997), "modelo quer dizer exemplar que se copia, ou imi- ta" e ensino quer dizer "instrução, educação". Logo, poderíamos dizer que modelo de ensino em $\mathrm{EaD}$ é um exemplar, uma forma de educação/instrução que se pode imitar. Uma forma/modelo de educação que se encontra influenciado por diferentes fatores e que deve ser muito bem pensado $e$ analisado continuamente para que não se contribua para uma educação a distância engessada visando à educação de massa.

Logo, torna-se importantíssimo o conhecimento dos diferentes modelos de Educação a Distância em diferentes ocasiões, como na montagem de um curso em EaD ou na simples escolha de uma instituição para estudar. Costa (2007) diz que os modelos de EaD devem se adequar às reais necessidades dos alunos $e$ regiões onde serão implantados;

identificando estas necessidades coerentes com as exigências legais, podemos destacar quatro concepções constitutivas básicas, que devem dominar ou orientar a escolha de modelos de qualidade em educação superior a distância, quais sejam (COSTA, 2007, p. 10):

- $\quad$ professores e alunos atuam em espaços distintos;

- $\quad$ necessidade de mediação tutorial;

- $\quad$ necessidade de apoio descentralizado ao estudante; e

- $\quad$ o aluno é o centro do processo pedagógico.

O autor ainda diz que

um modelo é um objeto que procura representar um processo real. Em sua construção, o primeiro passo consiste em abstrair da realidade aquelas variáveis consideradas fundamentais, as quais, em sua complexidade, com suas inter-relações e conexões, passam a integrar o modelo; e este é tanto mais satisfatório quanto maior sua capacidade de interpretar fielmente os fatos, inclusive antecipar fenômenos ainda não observados (COSTA, 2007, p. 9).

Podemos dizer que modelo de ensino é o modo/forma de ensino que influencia e é influenciado por vários fatores e mecanismos que fazem parte do processo de aprendizagem e da estrutura e organização do curso. Tais fatores implicam o pla- 
nejamento, os métodos e as técnicas de ensino, as formas e técnicas de avaliação, as formas de interação e, consequentemente, a construção do conhecimento durante o processo de ensino-aprendizagem. Behar (2009) entende o conceito de modelo pedagógico para Educação a Distância

\begin{abstract}
como um sistema de premissas teóricas que representa, explica e orienta a forma como se aborda o currículo e que concretiza as práticas pedagógicas e as interações professor/aluno/objeto de estudo. Nesse triângulo (professor, aluno e objeto) são estabelecidas relações sociais em que os sujeitos irão agir de acordo com o modelo definido (BEHAR, 2009, p. 24).
\end{abstract}

Os modelos de ensino estão direta $e$ indiretamente ligados à filosofia, à ideologia e ao papel social da instituição, o que afeta as escolhas pedagógicas, como a teoria pedagógica a ser seguida, avaliação, objetivos, procedimentos, abordagem e métodos de ensino que a instituição adotará no curso em EaD.

Refletir sobre os modelos de ensino implica repensar as práticas e diretrizes pedagógicas adotadas pela instituição.

Deve haver coerência entre o papel social da instituição, os objetivos do curso, as práticas pedagógicas do professor, as abordagens pedagógicas, posturas docentes, métodos de ensino-aprendizagem e métodos avaliativos que poderão ser colocados em prática pelo modelo de ensino adotado.

Alguns autores, professores, profissionais já mencionam em suas publicações modelos e abordagens em $\mathrm{EaD}$ que enriquecem as práticas e planejamentos de profissionais que atuam na modalidade, porém teorizar e esquematizar abordagens e modelos em $\mathrm{EaD}$ pode levar a um simplismo metódico, como se toda complexidade do processo de ensino-aprendizagem em Educação a Distância fosse resumido a uma simples receita de bolo. As abordagens e modelos são muitos, e é justamente essa variedade e a possibilidade de diversificar a metodologia que contribuem para qualidade da Educação a Distância.
A EaD, por conta de diferentes fatores (políticos, sociais, estéticos etc.), acaba caminhando, no Brasil, no mesmo percurso do ensino presencial.

Por conta de democratizar o ensino superior, dezenas de cursos superiores de graduação na modalidade a distância estão sendo implantados rapidamente, sem reflexão sobre como estão sendo organizados, e acabam seguindo metodologias simplistas, em que os alunos devem se enquadrar para ganhar um diploma exigido no mercado de trabalho capitalista.

Tutores que poderiam dar qualidade em sua prática e interação com alunos acabam se apegando apenas a questões burocráticas e administrativas de sua função por conta da quantidade de alunos que o sistema os impõe a tutorar. Mais uma vez por questões políticas, sociais, estéticas etc. o ensino pode perder na qualidade para ganhar na quantidade.

A EaD tem o potencial de ofertar um grande número de vagas na graduação, contribuindo para democratizar o ensino superior, porém tal processo de universalização do não pode ser atribuído apenas à $\mathrm{EaD}$ nem podemos achar que será da noite para o dia. Esse processo acelerado de expansão dos cursos de graduação a distância corre o risco de transformar a modalidade em "educação de massa", em que uma equipe pedagógica acaba sendo responsável por um número incompatível de alunos para que se tenha excelência na qualidade do ensino.

As abordagens e modelos devem ser vistos como possibilidades em uma prática que valoriza a práxis da prática pedagógica em todas as funções $e$ etapas do processo de ensino-aprendizagem em EaD, e não como únicos caminhos a seguir.

Devemos conhecê-las e adequá-las à realidade educacional, ao grupo de alunos, valorizando a cultura cotidiana e a realidade dos alunos envolvidos no processo.

\section{Os modelos ao longo da história}

As diferentes vertentes, concepções de aprendizagens, abordagens, modelos que a $\mathrm{EaD}$ pode seguir interferem diretamente na forma de interação e construção do conhecimento na modalidade. 
Conforme a própria história da EaD diz, a modalidade veio se modificando conforme as ferramentas foram surgindo e melhorando o processo de interação entre os participantes dos cursos (alunos, professores e demais profissionais).

Alguns autores dividem a história da $\mathrm{EaD}$ em diferentes gerações; podemos dizer que em cada momento histórico era praticado um modelo de EaD baseado nas tecnologias utilizadas para promover a interação.

Esses modelos classificados por gerações são referentes ao contexto histórico que a sociedade vivia em cada época. A EaD veio se adaptando e acompanhando as transformações políticas, econômicas $e$ sociais da sociedade e, com o passar dos anos, acabou utilizando diferentes ferramentas de comunicação para promover a interação nos cursos, o que acabou gerando diferentes modelos de $\mathrm{EaD}$ por conta da forma como se realizava a interação.

Em seu livro Educação a Distância, Maria Luiza Belloni menciona três modelos/gerações distintos de $\mathrm{EaD}$, que foram classificados conforme as tecnologias utilizadas em cada época para promover a interação entre os participantes do curso, principalmente entre professor e aluno. Essas classificações serão abordadas neste trabalho, sem desconsiderar que existem outras classificações de outros autores, como Cabral, Oliveira e Tarcia (2007), que dividem a $\mathrm{EaD}$ em quatro gerações, e Taylor (2001), que percebe a emergência da quinta geração em EaD (DIAS; LEITE, 2010).

$\mathrm{O}$ primeiro modelo ou geração seria o ensino por correspondência. Nesse modelo os estudantes receberiam o material de estudo por correio (que era a principal ferramenta de comunicação entre longas distâncias), estudavam sozinhos os conteúdos; as dúvidas dos alunos e as avaliações deveriam ser enviadas por correio - em alguns casos as avaliações tinham prazo de entrega.

Nesse modelo, o processo de construção do conhecimento era individual, e a autonomia nos estudos era essencial para que o aluno obtivesse êxito no processo de construção do conhecimento. Segundo Belloni (2009), a primeira geração, o ensino por correspondência, foi engendrado nos finais do século XIX pelo desenvolvimento da imprensa e dos caminhos de ferro. Nessa fase pioneira a interação entre professor e aluno era lenta, esparsa e limitada aos períodos em que os estudantes se submetiam aos exames previstos (EVANS; NATION, 1993: p.203 apud BELLONI, 2009. p.56).

O segundo modelo ou geração é o ensino multimeios a distância, desenvolvido ainda nos anos 1960. Esse modelo tinha como ferramenta principal de interação os meios de comunicação audiovisuais e computadores, além de material impresso e das correspondências via correio. Nas palavras de Belloni (2009),

o modelo da segunda geração - multimeios - desenvolveu-se a partir das orientações behavioristas e industrialistas típicas da época - pacotes instrucionais, público de massa, economia de escala -, integrando em maior ou menor medida as inovações tecnológicas de comunicação e informação, e ainda hoje é o modelo prevalente na grande maioria das experiências de $\mathrm{EaD}$. Seus meios principais são o impresso, programas de vídeo e áudio, difundidos via cassetes ou via antena (broadcasting) (BELLONI, 2009, p. 56).

A terceira geração ou modelo de ensino surge nos anos 1990 com o aparecimento das ferramentas web. O interessante nesse modelo é que a interação deixa de ter perfil de educação de massa e possibilita a interação personalizada.

De acordo com Belloni (2009),

A terceira geração de EaD começa a surgir nos anos 90, com o desenvolvimento e disseminação das NTIC, sendo muito mais uma proposta a realizar do que propriamente uma realidade a analisar. Seus meios principais são todos os anteriores mais os novos, o que implicará mudanças radicais nos modos de ensinar e aprender: unidades de curso concebidas sob a forma de programas interativos informatizados (que tendem a substituir as unidades de curso impressas); redes telemáticas com todas as suas potencialidades (banco de dados, e-mail, lista de discussão, sites etc.); CD-ROMs didáticos, de divulgação científica, cultural geral, de "infotenimento" (BELLONI, 2009, p. 57). 
Como vimos, com as constantes mudanças ocorridas na sociedade ao longo dos anos surgem novos meios de comunicação e tecnologias que modificam os processos de aprendizagem, principalmente na modalidade de Educação a Distância.

Segundo Moraes (2010),

\begin{abstract}
há muitas razões para observar atentamente os diferentes processos de evolução da $\mathrm{EaD}$. Uma delas é a percepção de que há mais de um caminho para essa evolução - diferentes modelos, com diferentes contextos, diferentes padrões de dificuldade na implementação e na aceitação (difusão) (MORAES, 2010, p. 30).
\end{abstract}

O que caracteriza os modelos de ensino mencionados são as tecnologias utilizadas em cada um para interação e construção do conhecimento durante o processo de ensino-aprendizagem.

A EaD existe há mais de 100 anos e em cada momento histórico desempenhou um perfil e um tipo de interação segundo as necessidades e possibilidades da época.

\section{A influência dos modelos industriais na EaD}

Maria Luiza Belloni expõe dois modelos ideológicos de EaD influenciados por modelos de produção industrial do século XX. Nesse sentido, a EaD teria dois modelos de organização: um, segundo Campion e Renner, citados por Belloni (2009), baseado no fordismo: "O fordismo, que propunha produção de massa para mercados de massa, se baseava em três princípios: baixa inovação dos produtos, baixa variabilidade dos processos de produção e baixa responsabilidade do trabalho" (CAMPION; RENNER, 1992: p. 12, apud BELLONI, 2009. p. 11). O segundo modelo seria o pós-fordismo, que, para Belloni (2009),

aparece como uma forma do capitalismo do futuro, "mais justo e democrático", e propõe também inovações nos dois primeiros fatores: alta inovação do produto e alta variabilidade do processo de produção, mas vai além do neofordismo e investe na responsabilização do trabalho (BELLONI, 2009. p. 12).
A EaD influenciada pelo modelo fordista está atrelada à hierarquização e à burocratização do ensino de forma centralizada. Seria uma educação padronizada nos moldes industriais, que visa baixos custos $e$ maior produção, o que remete a pensar na padronização dos meios de comunicação e aprendizagem. Para Belloni (2009),

a aplicação de modelos industriais e behavioristas à EaD não significa apenas o caráter passivo do estudante considerado como objeto e como um público de massa, mas envolve também o professor: "Proletarização, desqualificação, divisão do trabalho, democratização do espaço de trabalho e produção nova são aspectos da educação industrializada que implicam igualmente o professor $e$ o estudante" (RENNER, 1995, p. 292, apud BELLONI, 2009. p. 17).

Se analisarmos essa lógica organizacional e refletirmos sobre a interação dos participantes dos cursos em EaD, perceberemos que tal interação é programada e ineficiente para o processo de construção do conhecimento com qualidade. O estudante, apesar de estar em um curso a distância, acabaria tendo postura passiva no processo de socialização virtual, pois não teria a oportunidade de interagir livremente e socializar-se em uma estrutura padronizada, sem possibilidade de interação.

O professor não teria autonomia em suas ações (seguiria uma lógica de mercado visando à eficiência $e$ à quantidade em detrimento da qualidade) e seria limitado/obrigado a seguir o padrão estabelecido pela instituição.

Contrária a essa filosofia fordista, o pós-fordismo segue uma lógica de aprendizagem aberta, como expõe Campion, citado por Belloni (2009):

Um modelo pós-fordista de $\mathrm{EaD}$ teria que ser descentralizado e conservar a integração entre os diferentes modos de estudo (convencional e a distância). A equipe acadêmica deveria manter o controle e a autonomia com relação a seus cursos e, assim, poder ajustar rapidamente currículos e métodos, atendendo às necessidades cambiantes dos estudantes (CAMPION, 1993, p. 194, apud BELLONI, 2009, p. 19). 
Poderíamos dizer que nesse modelo de $\mathrm{EaD}$ os professores teriam mais autonomia no processo de ensino-aprendizagem que a estrutura curricular e métodos de ensino. Seria mais flexível à necessidade do aluno, que teria mais possibilidades de interação. Seria possível haver, entre os participantes dos cursos em EaD, descentralização da gestão e menos padronização.

Tais características facilitariam a interação de forma flexível e autônoma entre os alunos e professores dos cursos, o que melhoraria a qualidade da construção do conhecimento, interação e socialização do aluno.

Quando um modelo de ensino impossibilita a interação entre os participantes do curso, acaba empobrecendo o processo de ensino-aprendizagem, pois é na interação com o outro (objeto, material didático impresso, pessoas, meio ambiente etc.) que indivíduo aprende.

O conhecimento/conteúdo possui diferentes dimensões de aprendizagens (conceitual, atitudinal, procedimental), e quando o aluno é limitado à interação programada pode deixar de desenvolver o conhecimento nas diferentes dimensões. A interação, quando é limitada por ferramentas que não possibilitam a comunicação entre todos os participantes do processo de aprendizagem em $\mathrm{EaD}$, impede a troca de experiências, vivências e discussões que enriquecem a aprendizagem e promovem a reflexão sobre atitudes, conceitos e procedimentos, amadurecendo o processo de ensino-aprendizagem e desenvolvendo o conteúdo nas diferentes dimensões do saber.

\section{A contribuição de alguns autores}

\subsection{Os modelos de EaD segundo Mathias Gonzalez}

Mathias Gonzalez, em sua obra Fundamentos da Tutoria em Educação a Distância, classifica os modelos de curso baseado na forma de interação dos estudantes de EaD. São três formas distintas, chamadas Sala de Aula a Distância, Aprendizagem Independente e Aprendizagem Independente + Aula.

O primeiro modelo tem como princípio da interação o formato presencial. Os materiais são dispo- nibilizados para estudo dos alunos e são marcados encontros presenciais para debates e discussões dos conteúdos estudados. Os encontros seriam realizados em formato de aula. Nas palavras de Gonzalez (2005), o modelo em questão

estrutura-se nas tecnologias capazes de levar o conhecimento a pontos diferentes no país e no mundo. A instituição responsável pelo curso controla o andamento e o local onde deverá ser realizado o treinamento. As aulas envolvem comunicação síncrona: instrutores e estudantes combinam local e horário para se encontrar, uma vez por semana ou com outra regularidade. As instituições são capazes de atender a um pequeno número de alunos em cada local (GONZALEZ, 2005, p. 77).

A segunda classificação é a Aprendizagem Independente. A interação nesse modelo é mais ativa e constante, por não utilizar só momentos presenciais para construção coletiva do conhecimento, e exerce a prática da troca e interação durante toda a semana por meio das ferramentas online de interação. Segundo Gonzalez (2005),

\footnotetext{
os alunos podem fazer o curso independentemente do local onde estão e não precisam se adequar às escalas fixas de horários. Os estudantes recebem vários materiais de estudo, incluindo um programa de curso. A instituição coloca à disposição do aluno um monitor ou tutor que o acompanhará, fornecendo orientações, respostas e avaliando seus exercícios e testes. A interação entre o monitor e o estudante é viabilizada através de variadas tecnologias, tais como: telefone, fax, chats, correio eletrônico e correio tradicional. Não há aulas "no sentido clássico da palavra". Os alunos estudam de forma independente, buscando seguir o mais fielmente possível o programa do curso e podem interagir com o tutor e, alguns casos, com outros estudantes (GONZALEZ, 2005, p. 78).
}

A terceira e última classificação de Gonzalez é chamada de Aprendizagem Independente + Aula. Seria a união das duas classificações anteriores; ali a interação ocorre tanto por ferramentas síncronas como assíncronas. São utilizadas as ferramentas virtuais de interação e o encontro presencial em forma de aula e tutoria. Para Gonzalez (2005), 
este modelo envolve a utilização de material impresso e outras mídias, tais como fita de videocassete ou disquete de computador, CD-ROM ou DVD, que possibilitem ao aluno estudar no seu próprio ambiente. Outras tecnologias que envolvam os alunos também poderão ser utilizadas, como as descritas no Modelo 2. Os alunos reúnem-se periodicamente em grupos, em locais específicos, para receber apoio instrucional. Nas aulas discutem-se conteúdos, esclarecem-se conceitos, realizam-se trabalhos em grupo, experiências em laboratórios, simulações e outros exercícios relacionados com a aprendizagem (GONZALEZ, 2005, p. 78).

\subsection{A Pesquisa de Celso José da Costa}

Uma pesquisa interessante realizada por Celso José da Costa expõe os modelos nacionais precursores em EaD. Esses modelos foram organizados, estruturados e implantados de forma e em lugares diferentes, pois partiram de iniciativas distintas. Sem um modelo a seguir, as implantações dos cursos seguiram a necessidade e a possibilidade de cada região para sua implantação, o que gerou algumas variações e, consequentemente, modelos diferentes de EaD.

$\mathrm{O}$ autor estabelece quatro projetos precursores no sistema de EaD no Brasil: o curso de Pedagogia da UFMT (1995), o projeto Veredas, em Minas Gerais (2002), o projeto piloto do curso de administração do Banco do Brasil (2006) e o consórcio Cederj (2000).

Segundo Costa (2007), "as trajetórias desses projetos têm muitos pontos em comum e muitos outros distintos, que procuram dar respostas às condições geográficas e de público-alvo específicas e a necessidades diferenciadas de gestão" (COSTA, 2007, p. 13).

Observando os projetos pilotos estudados pelo autor, podemos constatar, além das diferenças já mencionadas, a questão da gestão coletiva e individual.

O curso de Pedagogia da Universidade Federal de Mato Grosso foi realizado e gerido por apenas uma instituição, enquanto o consórcio Cederj realiza uma gestão coletiva com a união de diferentes instituições públicas consorciadas, vinculadas ao Cederj.

Nesse caso podemos identificar dois modelos distintos de gestão e estruturação de cursos a distância: o coletivo e o individual, além da colaboração entre os três níveis de governo: municipal, estadual e federal.
Os modelos de gestão interferem na interação entre os alunos. $\mathrm{O}$ modelo de gestão coletiva como o Cederj possibilita imensa diversidade de opiniões, o que pode enriquecer a aprendizagem, porém os planejamentos são setoriais, realizados separadamente, o que pode interferir negativamente no processo de ensino-aprendizagem se as diferentes áreas do conhecimento e os diferentes gestores não dialogarem sobre os princípios da instituição.

O modelo de gestão individual não possui a preocupação de ser incoerente entre o desenvolvimento de uma disciplina e outra, pois possui a filosofia $e$ papel social de uma única instituição.

O interessante nesse conhecimento de gestão é o fato de a interação e as ferramentas utilizadas estarem diretamente relacionadas à filosofia da instituição que oferece o curso. As ferramentas e as formas de interação irão depender de uma série de fatores que cabe à gestão decidir, como o tipo de tecnologia, mão de obra, materiais didáticos etc.

\subsection{Modelos de EaD conforme José Manuel Moran}

Ainda diferenciando os modelos de Educação a Distância pela forma de interação utilizada, temos o autor José Manuel Moran, que, em Educação a Distância: pontos e contrapontos, obra organizada por Valéria Amorim Arantes, diz haver dois modelos de $\mathrm{EaD}$ predominantes no Brasil. Moran chama um de modelo Teleaula; o outro ele chama de modelo Web. O modelo Teleaula se assemelha à educação presencial: o professor leciona em um determinado lugar e as aulas são transmitidas ao vivo por satélite aos alunos em outros lugares. Esse modelo também utiliza videoaulas gravadas - aulas e vídeos gravados pelos professores e outros a que os alunos podem assistir juntos ou separados. Uma característica que ajuda a definir esse modelo é a função do professor, que se assemelha à do ensino presencial: o professor dá aulas que são transmitidas por aparelhos tecnológicos. Segundo Moran, 
no modelo Teleaula, os alunos vão a determinadas salas nos polos, em que assistem a aulas transmitidas por satélites ao vivo, uma ou duas vezes por semana. Eles enviam perguntas e o professor responde às que considera mais relevantes. Em geral, depois da teleaula, os alunos se reúnem em pequenos grupos para realizar as atividades de discussão $e$ aprofundamento de questões relacionadas com a aula dada, sob a supervisão de um mediador, chamado de professor-tutor local. Além das aulas, os alunos costumam receber material impresso e orientações de atividades para fazer durante a semana, individualmente, com o acompanhamento de um professor-tutor online ou eletrônico (MORAN, 2008, apud VALENTE et al, 2011, p. 48-49).

No chamado modelo Web a interação do professor com os alunos se faz por meio dos materiais didáticos $e$ as ferramentas da web. Nesse modelo o professor não dá aula; medeia de forma dialógica o aprendizado dos alunos. A função do professor é focada no acompanhamento e mediação da aprendizagem e construção do conhecimento do aluno. O professor é um motivador, incentivador da aprendizagem. Moran considera que

o modelo Web foca também no conteúdo disponibilizado pela internet e por CD ou DVD. Além do material encontrado na web, os alunos costumam ter material impresso por disciplina ou módulo. Os principais ambientes de aprendizagem são o Moodle, o Blackboard e o TelEduc. Algumas instituições tem seu próprio ambiente digital de aprendizagem. Começa-se a utilizar a webconferência para alguns momentos de interação presencial com os alunos, visando orientar, solucionar dúvidas e manter vínculos afetivos (VALENTE et al, 2011, p. 50).

O autor ainda classifica o modelo Web em duas vertentes que seriam dois outros modelos com focos e características distintos, como uma subdivisão do modelo Web: o mais virtual e o semipresencial. A dicotomia existente no modelo Web seria baseada na forma de interação entre professor, aluno e tutor. Enquanto o modelo mais virtual focaria a interação mediante os ambientes virtuais de aprendizagem, o modelo semipresencial teria encontros semanais presenciais com interação tanto no ambiente virtual quanto no presencial. Nas palavras de Moran, no primeiro, a orientação dos alunos é feita a distância, pela internet ou telefone. Os alunos se reportam ao professor e ao tutor durante o semestre e, em geral, se encontram presencialmente só para fazer as avaliações. É um modelo predominantemente via internet, e os encontros presenciais são mais espaçados, porque não existem os polos para o apoio semanal (VALENTE et al, 2011, p. 50).

No modelo semipresencial, que Moran exemplifica com o Consórcio Cederj, o autor diz que

os alunos têm polos perto de onde moram e, além do tutor online, há o tutor presencial no polo, com quem podem tirar dúvidas e participar das atividades solicitadas e dos laboratórios de informática e específicos do curso. Esse modelo é replicado pelas universidades públicas, sob a gestão da UAB, que fazem parcerias com as prefeituras para instalação dos polos de apoio presenciais (VALENTE et al, 2011, p. 50).

A contribuição de Moran ajuda a entender que os modelos de educação a distância, basicamente, são classificados e caracterizados pela forma de interação e ferramentas utilizadas para comunicação entre os participantes do curso.

\section{Conclusão}

A pretensão inicial da pesquisa foi investigar os modelos de EaD existentes no cenário educacional até o presente momento. Nesse sentido, devemos ter em mente que os modelos mencionados na pesquisa podem não ser únicos, tendo em vista as constantes mudanças e transformações que a sociedade e a educação sofrem, o que possibilita o surgimento de um novo modelo de ensino a qualquer momento.

Foram expostos ao longo da pesquisa dados informativos coletados ao longo dos doze últimos meses. Foram analisadas diferentes obras à procura de modelos de ensino em $\mathrm{EaD}$ e suas características, porém pouco foi encontrado a respeito do tema, que faz parte de uma dimensão específica da Educação a Distância, que pos- 
sui baixo número de publicações acadêmicas. Apesar disso, podemos dizer que essa realidade está mudando. $\mathrm{O}$ fato de a Educação a Distância estar crescendo e se expandindo rapidamente faz com que o mercado dê a importância necessária à modalidade e às suas dimensões, ampliando com isso aos poucos a discussão e as produções a respeito da $\mathrm{EaD}$ e suas características específicas, como os modelos de ensino.

Em grande parte, os modelos são definidos de acordo com a tecnologia utilizada para interação, o que remete a outra perspectiva: as tecnologias são altamente renováveis e o que hoje é moderno amanhã pode ser ultrapassado.

Nesse contexto, as reflexões sobre esta pesquisa não se esgotam aqui, pois os modelos tendem a se transformar, a se adequar às futuras tecnologias, o que implicará o surgimento de novos modelos de ensino. A tendência é que o governo dite as regras/diretrizes dos modelos de ensino em EaD por meio de decretos, resoluções, portarias e leis e com isso diminua as possíveis variações entre um modelo e outro.

Outro ponto que podemos destacar são os modelos de gestão, que interferem diretamente na forma de interação e as ferramentas que serão utilizadas para promover a interação entre os participantes. $\mathrm{O}$ gestor pode inibir ou promover manifestações acadêmicas, educacionais que estimulem a interação, a pesquisa e a educação. Pode seguir uma linha que visa lucros, promovendo uma EaD de massa, sem pensar no processo educacional de qualidade, e pode visar a uma Educação a Distância de qualidade, digna e igualitária, ajudando os professores e tutores com as ferramentas necessárias para personalizar o ensino, atendendo às questões culturais e heterogêneas de cada região. Enfim, a gestão, que pode ser coletiva ou individual, democrática ou autoritária, interfere diretamente na definição dos modelos de ensino em $\mathrm{EaD}$ e, consequentemente, no processo de ensino-aprendizagem da Educação a Distância.

Acredito que o presente estudo desperte a reflexão e ajude na construção de futuras pesquisas $e$ trabalhos sobre o tema em questão. O mundo se transforma, a sociedade se transforma e cabe à educação adaptar-se ao novo mundo, às novas ferramentas didáticas, criando e recriando novos modelos de ensino que atendam à necessidade atual dos cidadãos.

Espero que a pesquisa tenha contribuído para reflexão dos professores, tutores, estudantes e todos os profissionais que integram a equipe pedagógica e técnica em EaD sobre as formas de interação e sobre como as mesmas dependem do modelo de EaD utilizado para promover uma Educação a Distância de qualidade.

\section{Referências}

BEHAR, Patrícia Alejandra. Modelos pedagógicos em Educação a Distância. Porto Alegre: Artmed, 2009. BELLONI, Maria Luiza. Educação a Distância. São Paulo: Autores Associados, 2009.

COSTA, Celso José. Modelos de educação superior a distância e implementação da Universidade Aberta do Brasil. Revista Brasileira de Informática na Educação, v. 15, n² 2007.

DIAS, Rosilana Aparecida; LEITE, Lígia Silva. Educação a Distância: da legislação ao pedagógico. Petrópolis: Vozes, 2010.

GONZALEZ, Mathias. Fundamentos da tutoria em Educação a Distância. São Paulo: Avercamp, 2005. MORAES, Reginaldo C. Educação a Distância e ensino superior: introdução didática a um tema polêmico. São Paulo: Editora Senac São Paulo, 2010.

ROCHA, Ruth. Microdicionário. São Paulo: Scipione, 1997.

VALENTE, José Armando; MORAN, José Manuel; ARANTES, Valéria Amorim (orgs.). Educação a Distância: pontos e contrapontos. São Paulo: Summus, 2011. 